\title{
Zinc Chromate
}

National Cancer Institute

\section{Source}

National Cancer Institute. Zinc Chromate. NCI Thesaurus. Code C45893.

A yellowish, crystalline, inorganic compound that emits toxic chromium fumes upon heating. Zinc chromate is highly corrosive and is a strong oxidizing agent. This substance is used as a corrosion inhibitor, metal conditioner and is used in paints, varnishes and oil colors. Zinc chromate primarily affects the lungs causing shortness of breath, bronchitis, pneumonia and asthma but can also affect the gastrointestinal tract, liver, kidneys and immune system. This substance is a known human carcinogen and is associated with an increased risk of developing lung cancer and cancer of the sinonasal cavity. (NCI05) 